\title{
A Full Evaporation Static Headspace Gas Chromatography Method with Nitrogen Phosphorous Detection for Ultrasensitive Analysis of Semi-volatile Nitrosamines in Pharmaceutical Products
}

\author{
Jinjian Zheng, ${ }^{1,2}$ (1) Christine L. Kirkpatrick, ${ }^{1}$ Daniel Lee, ${ }^{1}$ Xinxin Han, ${ }^{1}$ Ana I. Martinez, ${ }^{1}$ Kimberly Gallagher, ${ }^{1}$ \\ Rebecca K. Evans, ${ }^{1}$ Sanjay V. Mudur, ${ }^{1}$ Xihui Liang, ${ }^{1}$ Jennifer Drake, ${ }^{1}$ Leah A. Buhler, ${ }^{1}$ and Mark D. Mowery ${ }^{1}$
}

Received 24 September 2021; accepted 16 November 2021; published online 6January 2022

\begin{abstract}
The recent detection of potent carcinogenic nitrosamine impurities in several human medicines has triggered product recalls and interrupted the supply of critical medications for hundreds of millions of patients, illuminating the need for increased testing of nitrosamines in pharmaceutical products. However, the development of analytical methods for nitrosamine detection is challenging due to high sensitivity requirements, complex matrices, and the large number and variety of samples requiring testing. Herein, we report an analytical method for the analysis of a common nitrosamine, N-nitrosodimethylamine (NDMA), in pharmaceutical products using full evaporation static headspace gas chromatography with nitrogen phosphorous detection (FE-SHSGC-NPD). This method is sensitive, specific, accurate, and precise and has the potential to serve as a universal method for testing all semi-volatile nitrosamines across different drug products. Through elimination of the detrimental headspace-liquid partition, a quantitation limit of $0.25 \mathrm{ppb}$ is achieved for NDMA, a significant improvement upon traditional LC-MS methods. The extraction of nitrosamines directly from solid sample not only simplifies the sample preparation procedure but also enables the method to be used for different products as is or with minor modifications, as demonstrated by the analysis of NDMA in 10+ pharmaceutical products. The in situ nitrosation that is commonly observed in GC methods for nitrosamine analysis was completely inhibited by the addition of a small volume solvent containing pyrogallol, phosphoric acid, and isopropanol. Employing simple procedures and low-cost instrumentation, this method can be implemented in any analytical laboratory for routine nitrosamine analysis, ensuring patient safety and uninterrupted supply of critical medications.
\end{abstract}

KEY WORDS: Full evaporation headspace sampling; Gas chromatography with nitrogen phosphorous detection; NDMA; Nitrosamine; Nitrosation inhibition.

Christine L. Kirkpatrick and Daniel Lee contributed equally to this work.

\section{Highlights}

- Superior sensitivity using full evaporation static headspace sampling with nitrogen phosphorous detection

- Elimination of analytical artifacts by completely inhibiting in situ nitrosation

- Minimal sample preparation and potential as a universal method for semi-volatile nitrosamines in different drug substances and drug products

- Low-cost instrumentation and easy implementation at analytical laboratories for routine testing

\footnotetext{
${ }^{1}$ Analytical Chemistry in Development and Supply, Merck Manufacturing Division, Merck \& Co., Inc., 126 E. Lincoln Ave, Rahway, New Jersey 07065, USA.

${ }^{2}$ To whom correspondence should be addressed. (e-mail: jinjian.zheng@merck.com)
}

\section{INTRODUCTION}

The discovery of N-nitrosodimethylamine (NDMA), a potent probable carcinogen with very low acceptable intake (AI) limits (e.g., $96 \mathrm{ng} /$ day), in valsartan has triggered industrywide scrutinization of nitrosamine contamination for all pharmaceutical products $(1,2)$. Since then, several drug products including sartans for hypertension, (3) metformin for diabetes (4), and ranitidine for heartburn (gastroesophageal reflux disease) (5) have been recalled due to unacceptable levels of NDMA. As new regulatory guidelines for nitrosamine risk require frequent testing in a broad range of pharmaceutical products, a fast, sensitive, and versatile analytical method is required to maintain supply. There are three major challenges in nitrosamine testing: (1) the array of products, (2) large number of batches to be tested, and (3) the high method sensitivity needed to meet regulatory expectations. There are approximately 1.13 billion people with hypertension (6) 
and over 463 million people with diabetes worldwide (7), and heartburn occurs in roughly 1.5 billion people on a weekly basis (8). Due to the widespread nature of these health issues, there are hundreds of thousands of batches of these drug products on the market. In addition, pharmaceutical companies need to perform confirmatory testing across multiple lots if a potential nitrosamine risk is identified in the drug product, which could affect a large portion of the product on the market or in development $(9,10)$. Furthermore, this is a rapidly evolving regulatory environment with major regulatory agencies actively revising guidance on the control of nitrosamines in human drugs. According to recent EMA guidance, drug manufacturers are required to demonstrate that the nitrosamine level is consistently below $10 \%$ of $\mathrm{AI}$ to justify omission of a specification (e.g., $4.8 \mathrm{ppb}$ NDMA in metformin $\mathrm{HCl}$ based on a maximum daily dose of $2 \mathrm{~g}$ ) (9). This is especially difficult for formulated drug products as extracting nitrosamines from complex matrices is much more difficult compared to drug substances.

Typically, nitrosamines are separated from sample matrix using liquid chromatography (LC) or gas chromatography (GC) and detected by a highly sensitive and specific detector. LC coupled with high resolution mass spectrometry (HRMS) is often used to achieve the desired sensitivity and selectivity (11-13). However, LC-HRMS is not widely available for routine use due to high instrument cost, high maintenance cost, and extensive analyst training. In addition, extensive sample preparation is required to minimize contamination to MS instrumentation, which limits the throughput. Although sensitive detection of nitrosamines using luminol chemiluminescence detection has been reported, the instrumentation is not commercially available (14). GC coupled with mass spectrometry (MS)(15), thermal energy analyzer (TEA)(16), nitrogen chemiluminescence detector (NCD), or nitrogen phosphorous detector (NPD)(17) have been used to analyze nitrosamines at $\mathrm{ng} / \mathrm{mL}$ level. However, the challenge with these GC methods often lies in how to effectively extract nitrosamines from the complex sample matrix and how to prevent in situ formation of nitrosamines (18). These approaches often lead to the development of specific LCor GC-MS methods for each product, which is timeconsuming due to the large array of pharmaceutical products. So far, testing for nitrosamines using MS-based methods is mainly performed in a specialized lab equipped with mass spectrometers qualified for GMP testing and specialized analysts trained in their operation. The release of these critical medications is often delayed due to the limited testing capacity, sample shipment, and other logistic issues.

Herein, we report an ultrasensitive and universal method for the detection of NDMA in different pharmaceutical products using a novel full evaporation static headspace GC method with nitrogen-phosphorous detection (FE-SHSGCNPD). The method sensitivity was improved by eliminating the headspace-liquid partition, and the in situ nitrosation, a common issue encountered in GC analysis of nitrosamines, was overcome by employing an effective inhibition scheme. The method performance characterization and potential application as a universal method for semi-volatile nitrosamines across different pharmaceutical products were demonstrated.

\section{EXPERIMENTAL}

Instrument. All studies were performed using an Agilent 7890B gas chromatography system equipped with nitrogen phosphorous detector and a 7697A headspace sampler, and all data were acquired using Waters Empower 3 software.

Sample Preparation. The experimental conditions for the analysis of NDMA in metformin products are as follows. The experimental conditions for other studies will be specified in the figure caption if they are different. One advantage of FE-SHS is the flexibility in sample size, which could be varied from sub $\mathrm{mg}$ to $\sim 100 \mathrm{mg}$ to achieve the desired sensitivity. The sensitivity in ppb is inversely proportional to sample size. The diluent contains $20 \mathrm{mg} /$ $\mathrm{mL}$ pyrogallol and $0.1 \% \mathrm{v} / \mathrm{v}$ phosphoric acid in isopropanol. Standard solutions were prepared at $50 \mu \mathrm{g} / \mathrm{mL}$ in isopropanol and then diluted with diluent to $20 \mathrm{ng} / \mathrm{mL}$. Reporting limit (sensitivity) solution was prepared by diluting the standard solution 1:10 to $2 \mathrm{ng} /$ $\mathrm{mL}$. Sample solutions were prepared by grinding the tablet into a fine powder and transferring a portion equivalent to $21 \pm 5 \mathrm{mg}$ metformin $\mathrm{HCl}$ into a $10 \mathrm{~mL}$ headspace vial. A pipette was used to accurately deliver $50 \mu \mathrm{L}$ of diluent into the headspace vial, which was immediately capped tightly for analysis. Refer to Supplemental Information 1 for details. Please note that nitrosamines are potent probable carcinogens and should be handled carefully according to the safety data sheet (SDS).

Headspace Parameters. The headspace vial volume was 10 $\mathrm{mL}$. The vial was heated in the headspace oven at $115^{\circ} \mathrm{C}$ for $15 \mathrm{~min}$ with high shaking. The sample loop volume was $1 \mathrm{~mL}$, with the injection loop temperature of $160^{\circ} \mathrm{C}$ and the transfer line temperature of $170^{\circ} \mathrm{C}$. Before injection, the vial was pressurized to $30 \mathrm{psi}$. The equilibration time was $0.1 \mathrm{~min}$, and the injection time was $0.5 \mathrm{~min}$. Refer to Supplemental Information 2.1 for details.

GC Parameters. All GC analysis was performed using a G16 column (e.g., Agilent DB-Wax), $30 \mathrm{~m} \times 0.25 \mathrm{~mm}$ I.D. and $0.5-\mu \mathrm{m}$ film thickness. Helium was used as the carrier gas at a constant flow rate of $3 \mathrm{~mL} / \mathrm{min}$. The $\mathrm{GC}$ inlet had a temperature of $200^{\circ} \mathrm{C}$ and a split ratio of 5:1. The oven was programed to hold $60^{\circ} \mathrm{C}$ for $1.5 \mathrm{~min}$, ramp at $20^{\circ} \mathrm{C} / \mathrm{min}$ to $150^{\circ} \mathrm{C}$, and then $40^{\circ} \mathrm{C} / \mathrm{min}$ to $240^{\circ} \mathrm{C}$ and hold for $3 \mathrm{~min}$ for a total run time of $11.25 \mathrm{~min}$. A nitrogen phosphorous detector with a BLOS bead was used for sensitive detection of nitrosamines, with a temperature setting of $330^{\circ} \mathrm{C}$, hydrogen (fuel) flow of $3 \mathrm{~mL} / \mathrm{min}$, air (oxidizer) flow of $60 \mathrm{~mL} / \mathrm{min}$, and constant makeup gas (nitrogen or helium) at $5 \mathrm{~mL} / \mathrm{min}$. An offset of $20 \mathrm{pA}$ was used and is recommended for future analysis. Refer to Supplemental Information 2.2 for details. Overlaid representative chromatograms are shown in Fig. S1.

\section{RESULTS AND DISCUSSION}

\section{Improved Sensitivity Using Full Evaporation Static Headspace (FE-SHS) Sampling}

Traditional static headspace (SHS) sampling is often not effective for the analysis of nitrosamines as they have 
relatively high boiling points (e.g., $151^{\circ} \mathrm{C}$ for NDMA, the smallest nitrosamine) and high partition coefficients in many sample diluents, thus resulting in low sensitivity (19). Inspired by the concepts of multiple headspace extraction (MHE)(20, 21) and the full evaporation technique (FET) (22-24), we propose a new headspace sampling technique for the analysis of nitrosamine in solid dose pharmaceutical products. It is essentially a headspace extraction of solid sample carried out in a single step instead of multi-steps in MHE, which reduces extraction time and improves the extraction efficiency and thus sensitivity. Samples are prepared by grinding tablets into a fine powder and transferring a small aliquot into a headspace GC vial. Nitrosamines are extracted to the headspace by heating at high temperature and analyzed by GC-NPD. The extraction time is dependent on the time it takes for the analytes of interest to diffuse from solid to headspace, which can be shortened by reducing the particle size through grinding and increasing the headspace heating temperature. The former is quite straightforward as most drug products can be easily ground into fine powder using mortar/pestle or mechanical grinder, but the effects of varying heating temperature are more complex. At low temperature, the diffusion is slow, and nitrosamines may adsorb to the solid sample matrix, which reduces method sensitivity. At high temperature, the sample matrix may decompose and interfere with peak of interest. Because the expected level of nitrosamine is extremely low $(<1 \mathrm{ppm})$, it is easy to drive all nitrosamines to the headspace even at low temperatures. This allows us to achieve sensitive detection of all tested nitrosamines at a headspace oven temperature below their boiling points. To quantitate nitrosamines, a small aliquot of external standard is added to the headspace vial and extracted using the same parameters. The volume of standard solution is small enough that it will be fully evaporated upon heating, akin to that in full evaporation technique (FET) (22-24). The same amount of diluent is added to the headspace vial containing the solid sample.

Fig. 1a shows a schematic comparison of traditional static headspace (SHS) sampling and full evaporation static headspace (FE-SHS) sampling. In traditional SHS, the analyte of interest with high boiling point (e.g., nitrosamine) mainly stays in the liquid phase due to its high partition coefficient, resulting in low sensitivity. In FE-SHS, analyte of interest and the solvent is fully evaporated into headspace, while the sample matrix is not volatilized. Without the undesirable partition, better sensitivity can be achieved even though a smaller amount of sample is used. Fig. 1b shows the comparison of sensitivity for the analysis of NDMA using SHS and FE-SHS. For static headspace sampling, $1 \mathrm{~mL}$ of 2 $\mathrm{ng} / \mathrm{mL}$ NDMA in DMSO was added to a $10 \mathrm{~mL}$ headspace vial, which corresponds to $20 \mathrm{ppb}$ NDMA with respect to 1 $\mathrm{mL}$ of $100 \mathrm{mg} / \mathrm{mL}$ sample. For FE-SHS, $50 \mu \mathrm{L}$ of $20 \mathrm{ng} / \mathrm{mL}$ NDMA in diluent containing $20 \mathrm{mg} / \mathrm{mL}$ pyrogallol and $0.1 \%$ phosphoric acid in IPA was added to a $10 \mathrm{~mL}$ headspace vial, which corresponds to $20 \mathrm{ppb}$ with respect to $50 \mathrm{mg}$ sample.

The sensitivity with FE-SHS is 38 times higher than SHS. The improved sensitivity in FE-SHS can be attributed to the elimination of headspace-liquid partition. In addition, the injection volume for SHS is limited due to "phase soaking" effect of condensed solvent $(25,26)$, while the injection volume can be easily increased for FE-SHS (e.g., from 1 to
$5 \mathrm{~mL}$ ) to further improve the sensitivity as IPA is volatile and does not exhibit this adverse effect. Fig. 1c shows the overlaid chromatograms of blank and NDMA standard solutions

a SHS

FE-SHS
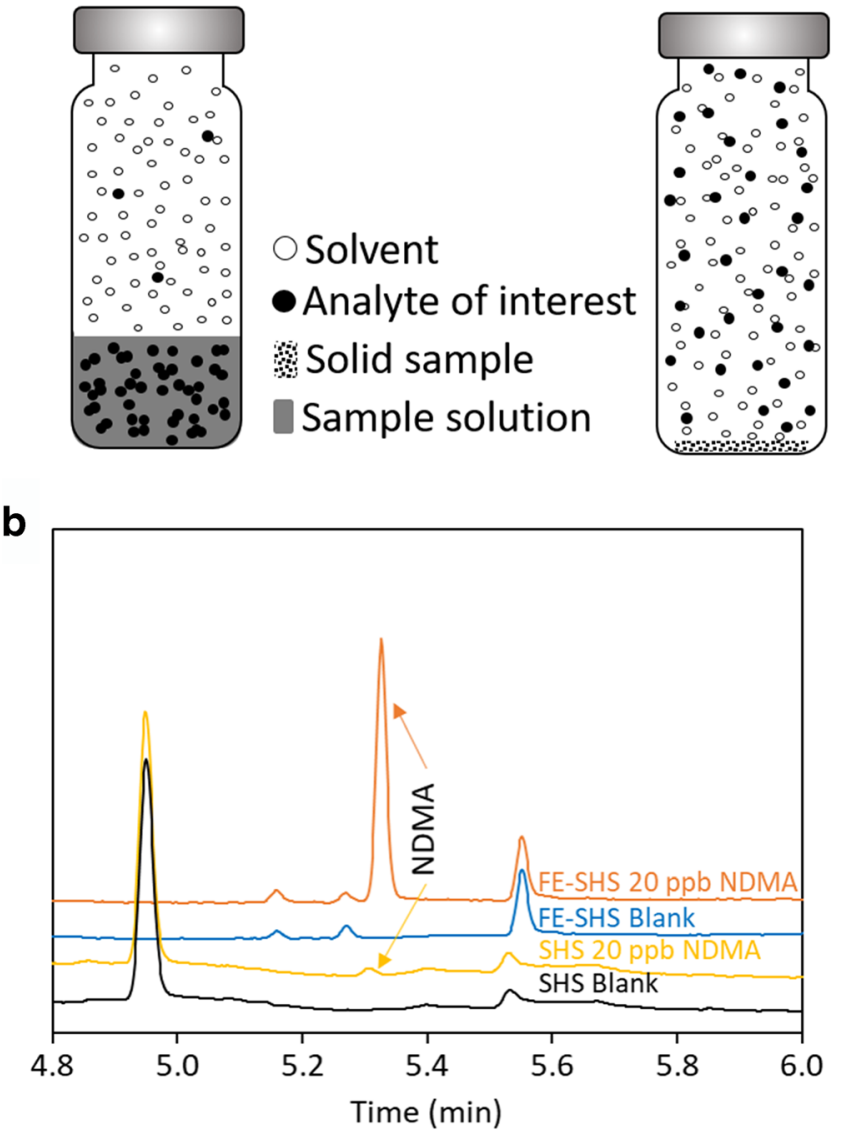

C

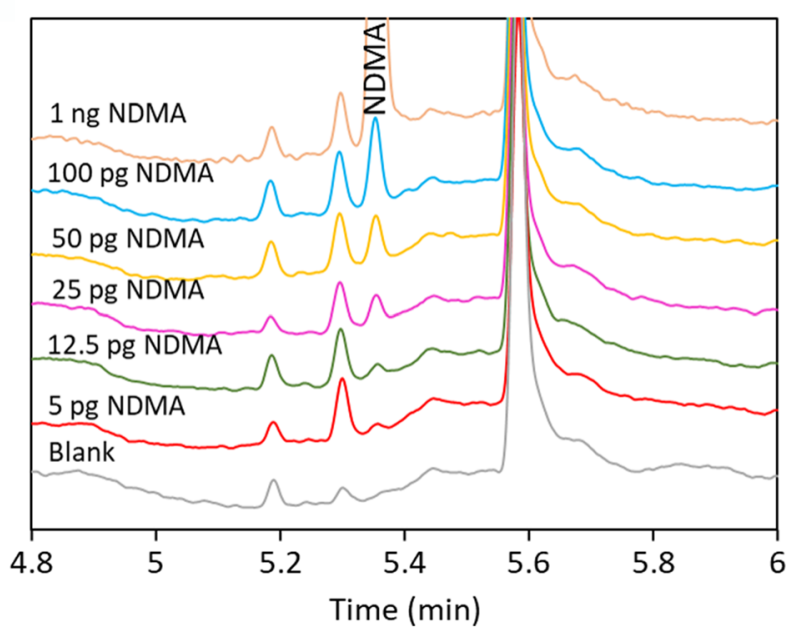

Figure 1. a Schematic illustration of traditional static headspace sampling (SHS) and full evaporation static headspace sampling (FESHS). b Comparison of SHS and FE-SHS for the analysis of NDMA. Experimental conditions are as described except for starting with an oven temperature of $50^{\circ} \mathrm{C}$ as opposed to $60^{\circ} \mathrm{C}$. c Overlaid chromatograms of NDMA standard solutions from $5 \mathrm{pg}$ to $1 \mathrm{ng}$ analyzed using FE-SHS-NPD 
obtained using FE-SHSGC-NPD ranging from $5 \mathrm{pg}$ to $1 \mathrm{ng}$ in a headspace vial, corresponding to 0.1 to $20 \mathrm{ppb}$ with respect to $50 \mathrm{mg}$ sample size. The detection limit (DL) and quantitation limit (QL) are estimated to be $0.1 \mathrm{ppb}$ and 0.25 ppb, based on a signal to noise ratio of $3: 1$ and 10:1, respectively, which is significantly more sensitive than those obtained using LC-HRMS method (QL: $30 \mathrm{ppb)} \mathrm{(27).} \mathrm{Refer}$ to Supplemental Information Fig. S2 for the integration and calculation of $\mathrm{s} / \mathrm{n}$ ratio for $\mathrm{QL}$ solutions. The sensitivity obtained using this method readily meets the regulatory requirement, e.g., $10 \% \mathrm{AI}$ or $4.8 \mathrm{ppb}$ NDMA in metformin $\mathrm{HCl}$ based on the AI of $96 \mathrm{ng}$ and a maximum daily dose of 2 g.

\section{Inhibition of In Situ Nitrosation}

One common issue during nitrosamine analysis is the in situ formation of nitrosamine from secondary amines that may be present in the drug substance with nitrosating agents such as nitrite which are ubiquitous in excipients (28). This is especially of high risk for headspace GC analysis due to extended heating at high temperature. This in situ formation of nitrosamine could cause false positives and incorrect rejection of acceptable products $(11,18)$. In order to quantitate nitrosamine accurately, in situ formation of nitrosamine must be eliminated. There have been tremendous efforts in the past to inhibit nitrosation of reactive amines in solution, but to our knowledge, there are a few reports on inhibiting the in situ formation of nitrosamine for analytical purposes (28-31). Several scavengers for nitrosating agents including pyrrole, 2,5-dimethylpyrrole, pyrogallol, phloroglucinol, caffeic acid, catechol, ascorbic acid, hydrazine, propyl gallate, and gallic acid have been evaluated for this method and were found to inhibit nitrosation at various levels. A combination of pyrogallol and phosphoric acid in isopropanol solvent was found to provide the best inhibition effect in solid matrix as shown in Fig. 2.

The metformin $\mathrm{HCl}$ reagent contains no NDMA based on testing using an LC-MS method (detection limit = $10 \mathrm{ppb}$ ) (27). However, when the same material was analyzed using FE-SHS-NPD method, 1000 ppb NDMA was detected using isopropanol as diluent, suggesting significant in situ formation. The NDMA level decreased to $28 \mathrm{ppb}$ when $20 \mathrm{mg} / \mathrm{mL}$ pyrogallol in IPA was used as diluent, which is still a false positive level due to in situ formation. When $20 \mathrm{mg}$ pyrogallol in $0.1 \%$ phosphoric acid in IPA was used as diluent, the NDMA level decreased to $0.7 \mathrm{ppb}$, which is below $10 \%$ of AI or $4.8 \mathrm{ppb}$. We believe that $0.7 \mathrm{ppb}$ NDMA is intrinsic in this material, but this cannot be verified as there is no other method that provides this level of sensitivity. As such, this combination of pyrogallol and phosphoric acid in IPA has effectively inhibited the in situ formation of nitrosation resulting from headspace extraction, limiting the potential for false positive. The nitrosation inhibition effect of phenolic compounds including pyrogallol has been reported previously (32-37). However, it is unexpected that the addition of acid further improves the inhibition effect as nitrosation often accelerates under acidic conditions (38). It is possible that dimethylamine, the precursor for NDMA, is fully protonated in the presence of $0.1 \%$ phosphoric acid, and the nitrosation proceeds extremely slowly, if at all. On the other hand,

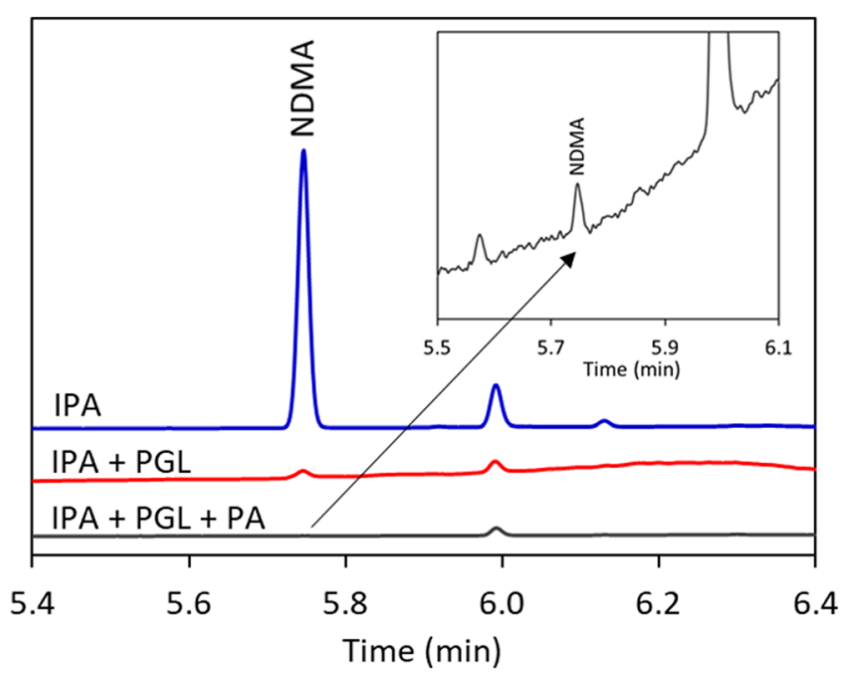

Figure 2. Inhibition of in situ formation of NDMA during analysis by FE-SHSGC-NPD. About $30 \mathrm{mg}$ metformin $\mathrm{HCl}$ drug substance was added to the headspace vial with $50 \mu \mathrm{L}$ diluent containing (1) isopropanol (IPA), (2) $20 \mathrm{mg} / \mathrm{mL}$ pyrogallol (PGL) in IPA (IPA + PGL), or (3) $20 \mathrm{mg} / \mathrm{mL}$ pyrogallol and $0.1 \%$ phosphoric acid (PA) in IPA (IPA + PGL + PA)

pyrogallol in acidic condition reacts readily and irreversibly with nitrosating agents, which are consumed almost completely (39). One benefit of using pyrogallol as nitrosation inhibitor is its low volatility and weak response on NPD, resulting in low baseline noise.

\section{Method Accuracy}

To demonstrate method accuracy, four lots of metformin $\mathrm{HCl}$ extended release drug products containing high levels of NDMA were analyzed using both a LC-HRMS method (27) and the FE-SHSGC-NPD method. The results were analyzed using JMP software 14.1.0 as shown in Figure 3a. The mean difference between two methods is $0.25 \mathrm{ppb}$, with a $95 \%$ confidence interval of $0.25 \pm 2.36 \mathrm{ppb}$ and a $p$-value of 0.7610 , suggesting that the difference between these two methods is due to random variations.

For FE-SHSGC-NPD analysis, it is necessary to grind the tablet into fine powder in order to facilitate the extraction of nitrosamines to headspace. The stability of the ground metformin extended release tablet at ambient temperature is shown in Figure $3 \mathrm{~b}$. The NDMA level decreased by about $0.57 \mathrm{ppb}$ or $2.8 \%$ per hour over the course of $5 \mathrm{~h}$. Although the difference is not considered significant, and may not be noticeable using a less sensitive method, a consistent trend was observed using the FESHSGC-NPD method. This demonstrates that the nitrosamines can be driven to headspace at sub-boiling point temperatures, which supports the underline principles of this method. For accurate quantitation, it is necessary to transfer the ground tablet powder into the headspace vial, add diluent, and close the vial as soon as possible.

One common issue for the quantitative MS analysis of nitrosamines is the requirement for the use of internal standard due to several limitations including sample volume expansion at high concentrations, evaporation (e.g., DCM extraction/reconstitution), and variations in ionization efficiency. All these concerns are not applicable to the FE- 

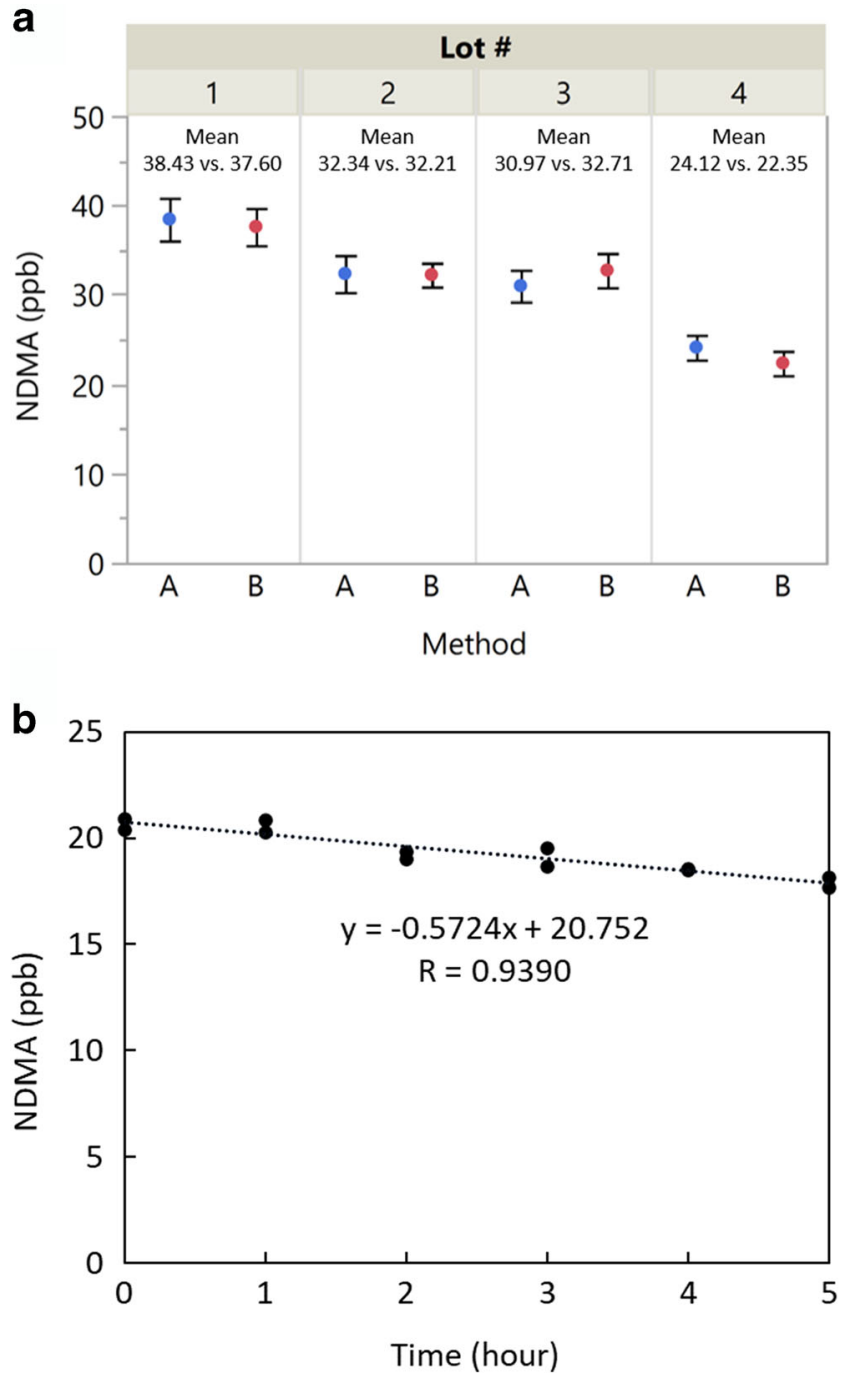

Figure 3. A Comparison of NDMA results using FE-SHSGC-NPD method (a) and LC-MS method (b). B Loss of NDMA in ground tablet powder across time, held at ambient temperature

SHSGC-NPD method due to elimination of sample extraction and lack of ionization of NPD. The \%RSD of bracketing standards across a 24 -h run is typically $<5 \%$, which is much tighter than the corresponding LC/MS and GC/MS method without internal standard and provides significant time and cost savings in QC environment.

\section{Method Universality}

For traditional methods, different sample preparation steps are often required for different drug products to extract nitrosamines from the sample matrix. However, there is no need for sample extraction prior to analysis using this method, making it a potentially universal method to analyze NDMA in different drug substances and drug products as is or with minor modifications. In addition, this sample preparation method is particularly advantageous for samples that are prone to gelling, especially in the presence of water.

Fig. 4a shows the analysis of NDMA in 10 different drug products containing metformin $\mathrm{HCl}$, and Fig. 4b shows the analysis of NDMA in valsartan drug substances using the same FE-
SHSGC-NPD method. The NDMA levels range from $<1$ to $5 \mathrm{ppb}$ for metformin $\mathrm{HCl}$ drug products. The NDMA results are 4 and $6900 \mathrm{ppb}$ for valsartan drug substance lot A and valsartan drug substance lot B, respectively. The same method has also been successfully applied to detect NDMA in multiple drug substances in development stage, in which the risk of NDMA contamination was identified. These results demonstrated the potential universality of this method.

This method was also applied to detect NDMA in ranitidine $\mathrm{HCl}$ with minor modifications. $\mathrm{GC}$ is generally considered unsuitable for the analysis of NDMA in ranitidine as it is known that ranitidine degrades at elevated temperature to form NDMA, causing analytical artifact $(5,18)$. Abe et al. reported over 100-fold increase of NDMA during headspace GC-MS analysis when the headspace oven temperature was increased from 80 to $110^{\circ} \mathrm{C}$ (40). When the method described in Fig. 4a was applied to analyze NDMA in a ranitidine $\mathrm{HCl}$ drug substance, about 28.3 to $52.0 \mathrm{ppm}$ NDMA was detected, compared to $13.2 \mathrm{ppm}$ obtained using

a

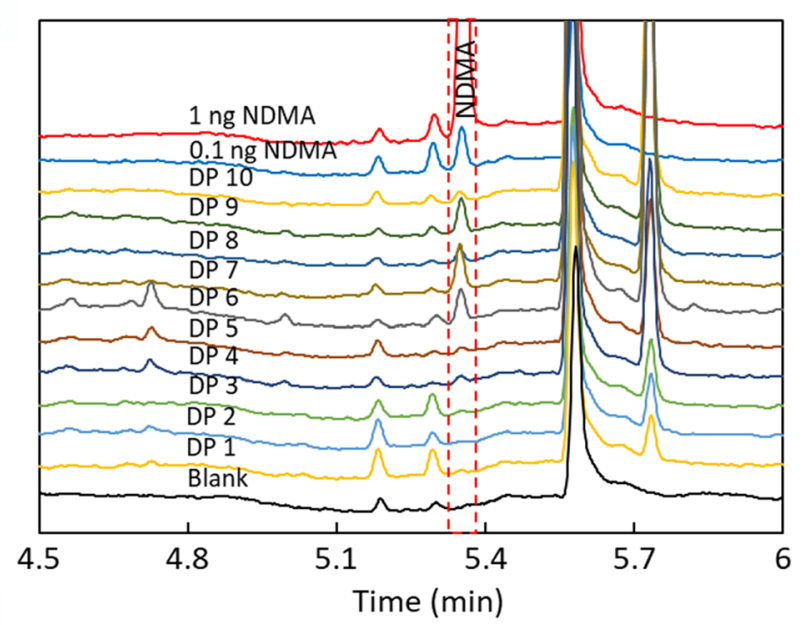

b

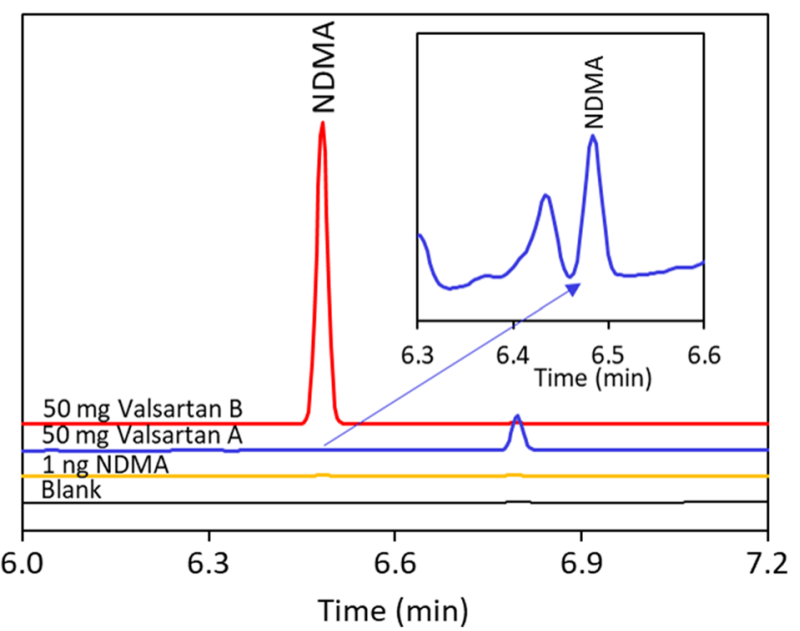

Figure 4. a Analysis of 10 different fixed dose combination drug products containing metformin $\mathrm{HCl}$ using FE-SHSGC-NPD method. b Analysis of NDMA in valsartan drug substances. The oven temperature is held at $50^{\circ} \mathrm{C}$ for $1.5 \mathrm{~min}$, then ramped by $15^{\circ} \mathrm{C} / \mathrm{min}$ to $150^{\circ} \mathrm{C}$, followed by $40^{\circ} \mathrm{C} / \mathrm{min}$ to $240^{\circ} \mathrm{C}$, and finally held at $240^{\circ} \mathrm{C}$ for $3 \mathrm{~min}$. Approximately $50 \mathrm{mg}$ valsartan drug substance was used for analysis 


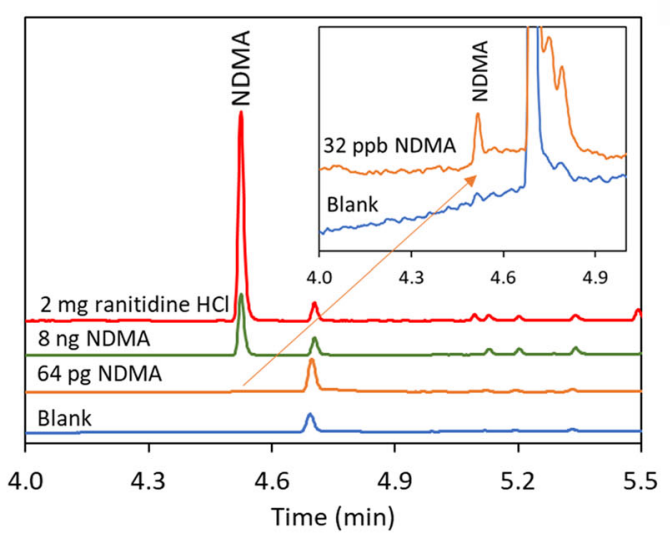

b

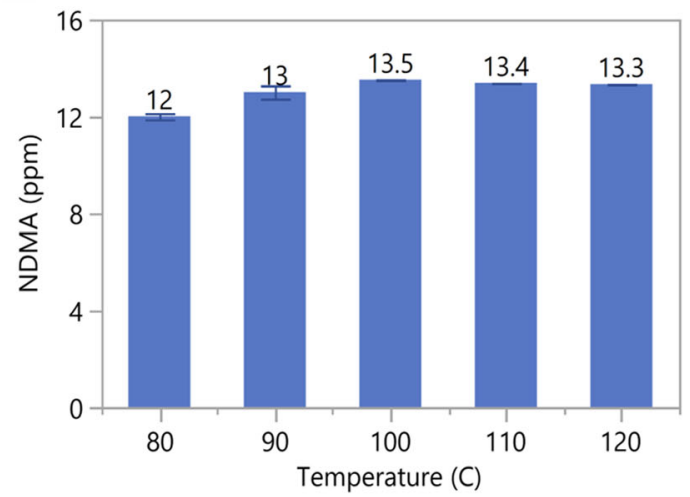

C

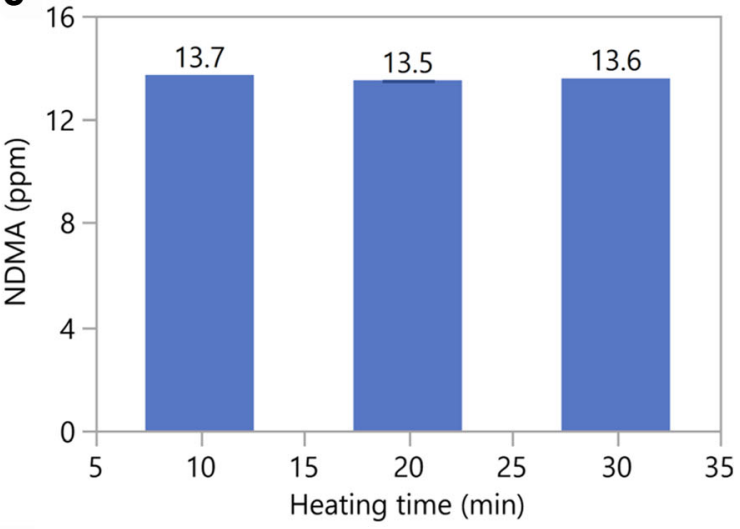

d

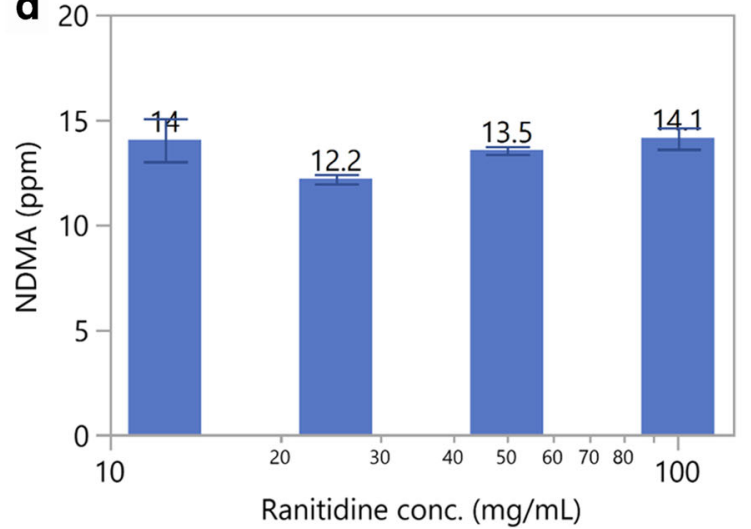

Figure 5. a Analysis of NDMA in ranitidine $\mathrm{HCl}$ drug substance. The oven temperature is held at $60^{\circ} \mathrm{C}$ for 1.5 min, then ramped by $30^{\circ} \mathrm{C} / \mathrm{min}$ to $240^{\circ} \mathrm{C}$, and finally held at $240^{\circ} \mathrm{C}$ for $2 \mathrm{~min}$. For sample preparation, $50 \mathrm{mg} / \mathrm{mL}$ ranitidine $\mathrm{HCl}$ was dissolved in a diluent containing $100 \mathrm{mg} / \mathrm{mL}$ pyrogallol, $20 \mathrm{mg} / \mathrm{mL}$ diphenylamine, and $0.1 \%$ phosphoric acid in methanol. For GC analysis, $40 \mu \mathrm{L}$ sample solution was transferred into a $20-\mathrm{mL}$ headspace vial. The vial is equilibrated at $100^{\circ} \mathrm{C}$ for 20 min. b Analysis of NDMA in ranitidine $\mathrm{HCl}$ using FE-HSGC-NPD with different headspace oven temperatures from 80 to $120^{\circ} \mathrm{C}$. c Analysis of NDMA in ranitidine $\mathrm{HCl}$ using FE-HSGC-NPD with different equilibration times from 10 to 30 min. d Analysis of NDMA in ranitidine $\mathrm{HCl}$ using FE-HSGC-NPD with different sample concentrations ranging from 12.5 to 100 $\mathrm{mg} / \mathrm{mL}$

LC-MS method, indicating analytical artifact due to in situ NDMA formation. To accurately quantitate NDMA in ranitidine using FE-HSGC-NPD method, the diluent was modified to include $100 \mathrm{mg} / \mathrm{mL}$ pyrogallol, $20 \mathrm{mg} / \mathrm{mL}$ diphenylamine, and $0.1 \%$ phosphoric acid in methanol, and the ranitidine $\mathrm{HCl}$ sample size was reduced from 50 to $2 \mathrm{mg}$. The increased ratio of pyrogallol to sample size $(125 \times)$ further improves the scavenging efficiency of nitrosating agents. The addition of diphenylamine ensures that remaining nitrosating agents are completely consumed before they react with residual dimethylamine in ranitidine as diphenylamine is a weaker base (pKa 0.8) and thus a much more reactive nitrosating substrate under acidic conditions (38). The results are shown in Fig. 5a. The method quantitation limit is $32 \mathrm{ppb}$ NDMA with respect to $2 \mathrm{mg}$ ranitidine $\mathrm{HCl}$ sample, which is $10 \%$ of the AI limit of $320 \mathrm{ppb}$. The NDMA results in ranitidine $\mathrm{HCl}$ drug substance is $13.5 \mathrm{ppm}$, which matches well with the result of $13.2 \mathrm{ppm}$ obtained using LC-HRMS. The in situ formation of NDMA was completely inhibited, evidenced by the consistent NDMA results obtained under varied conditions including (1) varying the headspace oven temperature between 80 and $120^{\circ} \mathrm{C}$ (Fig. 5b), (2) changing the headspace equilibration time from 10 to $30 \mathrm{~min}$ (Fig. $5 \mathrm{c}$ ), and
(3) changing the sample concentration from 12.5 to $100 \mathrm{mg} /$ $\mathrm{mL}$ (Fig. $5 \mathrm{~d}$ ). Considering that ranitidine is one of the most difficult compounds for GC analysis, we believe that the results above serve as strong testimonies of the universal applicability of this FE-HSGC-NPD method.

For the results shown in Fig. 5, ranitidine $\mathrm{HCl}$ drug substance was dissolved in diluent and pipetted into the headspace vial instead of weighing small quantity of each sample separately ( 0.5 to $4 \mathrm{mg})$. Therefore, the sample extraction appears to be similar to FET proposed by Markelov (21). However, in practice, the solid sample can be weighed into the headspace vial with subsequent addition of diluent to dissolve it to avoid additional extraction step, especially for drug product. To minimize analytical variability due to small sample size, the sample should be homogenized thoroughly, and duplicate analyses should be performed.

In addition, this method can be applied to analyze other common nitrosamines with established AIs including $\mathrm{N}$ nitrosodiethylamine (NDEA), N-nitrosoethylisopropylamine (NEIPA), N-nitrosodiisopropylamine (NDIPA), Nnitrosodibutylamine (NDBA), N-nitrosomethylphenylamine (NMPA), and N-nitrosomorpholine(NMORP) as shown in Figure 6. Higher headspace oven temperatures may be 


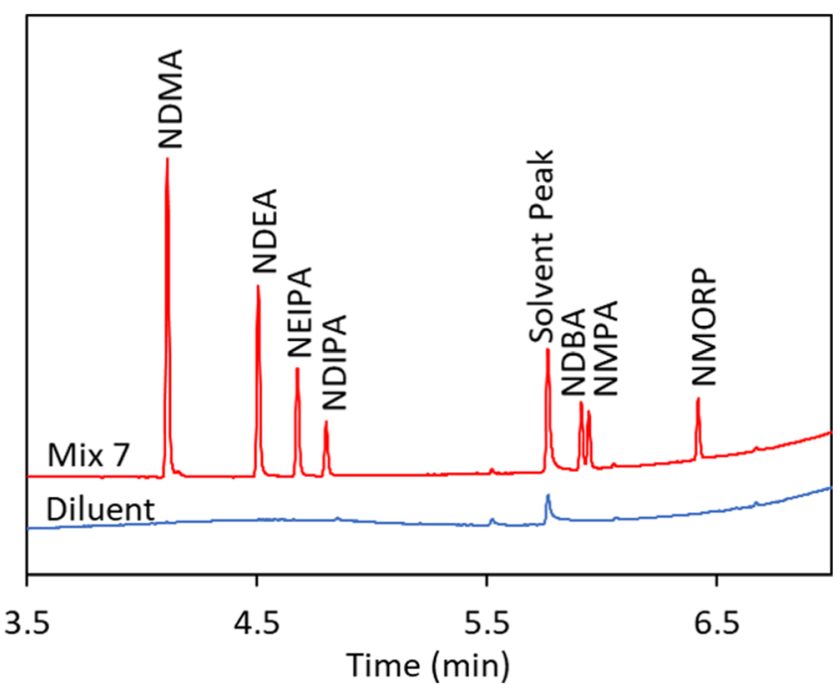

Figure 6. Analysis of seven common nitrosamines including NDMA, NDEA, NEIPA, NDIPA, NDBA, NMPA, and NMORP using FESHSGC-NPD. The carrier gas is helium at constant flow rate at $2 \mathrm{~mL} /$ $\mathrm{min}$. The oven temperature is held at $70^{\circ} \mathrm{C}$ for $1 \mathrm{~min}$, then ramped by $25^{\circ} \mathrm{C} / \mathrm{min}$ to $240^{\circ} \mathrm{C}$, and finally held at $240^{\circ} \mathrm{C}$ for $1 \mathrm{~min}$. The diluent contains $20 \mathrm{mg} / \mathrm{mL}$ pyrogallol and $0.1 \%$ phosphoric acid in IPA. The standard solution contains $500 \mathrm{ng} / \mathrm{mL}$ each of NDMA, NDEA, NEIPA, NDIPA, NDBA, NMPA, and NMORP, and $40 \mu \mathrm{L}$ is added to a $20-\mathrm{mL}$ headspace vial, capped and crimped tightly. The vial is heated at $150^{\circ} \mathrm{C}$ for $30 \mathrm{~min}$, and $1 \mathrm{~mL}$ headspace is injected with a split ratio of $20: 1$

required to minimize the adsorption to the solid matrix for nitrosamines with high boiling points.

The method has been validated according to $\mathrm{ICH}$ guideline and has been demonstrated to be sensitive, specific, accurate, and precise as shown in the summary of method validation results (Table S1). It has been used successfully to test 795 batches of commercial metformin $\mathrm{HCl}$ products in 11 days on one headspace GC instrument including both instant and extended release formulations, demonstrating the capability for high-throughput analysis.

\section{CONCLUSIONS}

In conclusion, a sensitive FE-SHSGC-NPD method was developed to analyze NDMA in pharmaceutical products. This new method boasts simple sample preparation, low-cost instrumentation (same cost as headspace GC-FID), and easy data processing, making it an ideal choice for routine testing at any analytical laboratory. The analytical artifact that is often encountered during nitrosamine analysis is eliminated with efficient inhibition of in situ nitrosation. The method has been successfully applied to test for NDMA in different drug products and drug substances including the very difficult ranitidine $\mathrm{HCl}$, demonstrating the potential as a universal method for different pharmaceutical products. Widespread adoption of this technique for nitrosamine analysis could play a key role to ensure patient safety, expedite drug development process, and minimize the interruption to the supply of critical medications. Other application of this technique may include the analysis of trace level impurities with moderate volatility beyond nitrosamines.

\section{SUPPLEMENTARY INFORMATION}

The online version contains supplementary material available at https://doi.org/10.1208/s12248-021-00669-8.

\section{ACKNOWLEDGEMENTS}

The authors would like to thank Jackson Hall and Tessa Carducci from Merck \& Co., Inc., Rahway, NJ, USA, and Grace Chen from Merck \& Co., Inc., West Point, PA, USA, respectively, for critical review of manuscript and invaluable discussions.

\section{AUTHOR CONTRIBUTION}

All authors contributed to the conception and design of this manuscript. JZ, CLK, DL, and $\mathrm{XH}$ authored the manuscript. JZ, AIM, and DH acquired data for this manuscript. All authors reviewed, edited, and approved the manuscript. JZ is the corresponding author for the manuscript.

\section{FUNDING}

Funding for this study was provided by Merck \& Co., Inc., Rahway, NJ, USA.

\section{DECLARATIONS}

Conflict of interest The authors declare no competing interests.

\section{REFERENCES}

1. International Agency for Research on Cancer, "IARC monographs on the identification of carcinogenic hazards to humans", https://monographs.iarc.who.int/list-of-classifications

2. Peto R, Gray R, Brantom P, Grasso P. Dose and time relationships for tumor induction in the liver and esophagus of 4080 inbred rats by chronic ingestion of N-nitrosodiethylamine or N-nitrosodimethylamine. Cancer Res. 1991;51:6452-69.

3. Food and Drug Administration, (FDA), "FDA updates and press announcements on angiotensin II receptor blocker (ARB) recalls (Valsartan, Losartan, and Irbesartan)", https:// www.fda.gov/drugs/drug-safety-and-availability/fda-updatesand-press-announcements-angiotensin-ii-receptor-blocker-arbrecalls-valsartan-losartan

4. Food and Drug Administration, (FDA), "FDA updates and press announcements on NDMA in metformin", https:// www.fda.gov/drugs/drug-safety-and-availability/fda-updatesand-press-announcements-ndma-metformin

5. Food and Drug Administration, (FDA), "FDA updates and press announcements on NDMA in ranitidine (Zantac)", https:// www.fda.gov/drugs/drug-safety-and-availability/fda-updatesand-press-announcements-ndma-zantac-ranitidine

6. World Health Organization, (WHO), "Hypertension", https:// www.who.int/news-room/fact-sheets/detail/hypertension

7. International Diabetes Federation, "Diabetes facts \& figures", https://www.idf.org/aboutdiabetes/what-is-diabetes/factsfigures.html

8. Locke GR, Talley NJ, Fett SL, Zinsmeister AR, Melton LJ. Prevalence and clinical spectrum of gastroesophageal reflux: a population-based study in Olmsted County, Minnesota. Gastroenterology. 1997;112:1448-56. 
9. European Medicines Agency, (EMEA), "Procedure under Article 5(3) of Regulation EC (No) 726/2004, Nitrosamine impurities in human medicinal products", EMEA/H/A-5(3)/ 1490, 25 June 2020.

10. Food and Drug Administration, (FDA), "FDA guidance for industry, control of nitrosamine impurities in human drugs", Sept., 2020.

11. Yang J, Marzan TA, Ye W, Sommers CD, Rodriguez JD, Keire DA. A cautionary tale: quantitative LC-HRMS analytical procedures for the analysis of $N$-nitrosodimethylamine in metformin. AAPS J. 2020;22:89.

12. Ripollés C, Pitarch E, Sancho JV, López FJ, Hernández F. Determination of eight nitrosamines in water at the $\mathrm{nLL}^{-1}$ levels by liquid chromatography coupled to atmospheric pressure chemical ionization tandem mass spectrometry. Anal Chim Acta. 2011;702:62-71.

13. European Directorate for the Quality of Medicines \& Health Care, (EDQM), "Ad-hoc projects of the OMCL Network", https://www.edqm.eu/en/ad-hoc-projects-omcl-network.

14. Kodamatani H, Roback S, Plumlee M, Ishida K, Masunaga H, Maruyama N, Fujioka T. An inline ion-exchange system in a chemiluminescence-based analyzer for direct analysis of $\mathrm{N}$ nitrosamines in treated wastewater. J Chromatogr A. 2018; $1553: 51-6$.

15. Dong H, Guo X, Xian Y, Luo H, Wang B, Wu Y. A salting outacetonitrile homogeneous extraction coupled with gas chromatography-mass spectrometry method for the simultaneous determination of thirteen N-nitrosamines in skin care cosmetics. J Chromatogr A. 2015;1422:82-8.

16. Fine DH, Rufeh F, Lieb D, Rounbehler DP. Description of the thermal energy analyzer (TEA) for trace determination of volatile and nonvolatile N-nitroso compounds. Anal Chem. 1975:47:1188-91.

17. Grebel JE, Suffet IH. Nitrogen-phosphorus detection and nitrogen chemiluminescence detection of volatile nitrosamines in water matrices: optimization and performance comparison. J Chromatogr A. 2007;1175:141-4.

18. Zeng T, Mitch WA. Oral intake of ranitidine increases urinary excretion of $\mathrm{N}$-nitrosodimethylamine. Carcinogenesis. 2016;37:625-34. Retraction notice: Carcinogenesis, bgab029. https://doi.org/10.1093/carcin/bgab029.

19. Kolb B, Ettre LS. Static headspace - gas chromatography: theory and practice. 2nd ed. Wiley-Interscience; 2006.

20. Hakkarainen M. Developments in multiple headspace extraction. J Biochem Biophys Methods. 2007;70:229-33.

21. Markelov M. Matrix independent headspace gas chromatographic analysis. The full evaporation technique. Anal Chim Acta. 1993;276:235-45.

22. Schuberth J. Volatile organic compounds determined in pharmaceutical products by full evaporation technique and capillary gas chromatography/ion-trap detection. Anal Chem. 1996; $68: 1317-20$.

23. Brault A, Agasse V, Cardinael P, Combret J. The full evaporation technique: a promising alternative for residual solvents analysis in solid samples. J Sep Sci. 2005;28:380-6.

24. Boxtel N, Wolfs K, Schepdael A, Adams E. Evaluation of the full evaporation technique for quantitative analysis of high boiling compounds with high affinity for apolar matrices. J Chromatogr A. 2014;1348:63-70.

25. Grob K Jr. Broadening of peaks eluted before the solvent in capillary GC, Part II: The role of phase soaking. Chromatographia. 1983;17:361-7.
26. Grob K Jr, Schilling B. Observation of a peak under the action of "phase soaking", a gas chromatographic solvent effect, during passage through a capillary column. J Chromatogr. 1983;259:3748.

27. Food and Drug Administration, (FDA), "Liquid chromatography-high resolution mass spectrometry (LCHRMS) method for the determination of NDMA in metformin drug substance and drug product", https://www.fda.gov/media/ 134914/download.

28. ACS SYMPOSIUM SERIES 553. In: Loeppky RN, Michejda CJ, editors. Chapter 5 Nitrosamines and related N-nitroso compounds: chemistry and biochemistry; March 1994. p. 52-65.

29. Wilcox AL, Bao YT, Loeppky RN. Pyrroles as effective agents for blocking amine nitrosation. Chem Res Toxicol. 1991;4:37381.

30. Choi JS, Park SH, Choi JH. Nitrite scavenging effect by flavonoids and its structure-effect relationship. Arch Pharm Res. 1989;12:26-33.

31. Fritzsche M, Blom G, Keitel J, Goettsche A, Seegel M, Leicht S, Guessregen B, Hickert S, Reifenberg P, Cimelli A, Baranowski R, Desmartin E, Barrau E, Harrison M, Bristow T, O'Neill N, Kirsch A, Krueger P, Saal C, et al. NDMA analytics in metformin products: comparison of methods and pitfalls. Eur J Pharm Sci. 2021;168:106026. https://doi.org/10.1016/ j.ejps.2021.106026.

32. Wainright $\mathrm{T}$. The chemistry of nitrosamine formation: relevance to malting and brewing. J Inst Brew. 1986;92:49-64.

33. Yamada T, Yamamoto M, Tanimura A. Studies on the formation of nitrosamines (VII): the effects of some polyphenols on nitrosation of diethylamine. J Food Hyg Soc. 1978;19:224-7.

34. Rundlöf T, Olsson E, Wiernik A, Back S, Aune M, Johansson L, Wahlberg I. Potential nitrite scavengers as inhibitors of the formation of $\mathrm{N}$-nitrosamines in solution and tobacco matrix systems. J Agric Food Chem. 2000;48:4381-8.

35. Mori Y, Mitani A. Reaction of nitrite with polyphenols. J Jpn Soc Nutr Food Sci. 1980;33:81-6.

36. De Lucia M, Panzella L, Crescenzi O, Napolitano A, Baroneb $\mathrm{V}$, d'Ischiaa $\mathrm{M}$. The catecholic antioxidant piceatannol is an effective nitrosation inhibitor via an unusual double bond nitration. Bioorg Med Chem Lett. 2006;16:2238-42.

37. González-Mancebo S, García-Santos MP, Hernández-Benito J, Calle E, Casado J. Nitrosation of phenolic compounds: inhibition and enhancement. J Agric Food Chem. 1999;47:2235-40.

38. Mirvish SS. Formation of N-nitroso compounds: chemistry, kinetics, and in vivo occurrence. Toxicol Appl Pharmacol. 1975;31:325-51.

39. Panzella L, Manini P, Napolitano A, d'Ischia M. The acidpromoted reaction of the green tea polyphenol epigallocatechin gallate with nitrite ions. Chem Res Toxicol. 2005;18:722-9.

40. Abe Y, Yamamoto E, Yoshida H, Usui A, Tomita N, Kanno H, Masada S, Yokoo H, Tsuji G, Uchiyama N, Hakamatsuka T, Demizu Y, Izutsu KI, Goda Y, Okuda H. Temperaturedependent formation of $\mathrm{N}$-nitrosodimethylamine during the storage of ranitidine reagent powders and tablets. Chem Pharm Bull. 2020;68:1008-12.

Publisher's Note Springer Nature remains neutral with regard to jurisdictional claims in published maps and institutional affiliations. 